\title{
Erratum to: Non-attendance at diabetic eye screening and risk of sight-threatening diabetic retinopathy: a population-based cohort study
}

\author{
Alice S. Forster • Angus Forbes • Hiten Dodhia • \\ Clare Connor • Alain Du Chemin • Sobha Sivaprasad • \\ Samantha Mann • Martin C. Gulliford
}

Published online: 5 July 2013

(C) Springer-Verlag Berlin Heidelberg 2013

Erratum to: Diabetologia

DOI 10.1007/s00125-013-2975-0

Unfortunately Dr H. Dodhia's address was incomplete in the original paper. The correct affiliation list is shown here.

The online version of the original article can be found at http://dx.doi.org/ 10.1007/s00125-013-2975-0.

\footnotetext{
A. S. Forster $(\bowtie) \cdot$ M. C. Gulliford

Department of Primary Care and Public Health Sciences,

King's College London, Capital House, 42 Weston Street,

London SE1 3QD, UK

e-mail: alice.s.forster@kcl.ac.uk

\author{
A. Forbes \\ Diabetes, Endocrinology and Metabolism, Nutrition, Obesity, \\ Vision and Related Surgeries Clinical Academic Group, \\ Department of Primary and Intermediate Care, \\ King's College London, London, UK \\ H. Dodhia \\ Lambeth and Southwark Directorate of Public Health, London, UK \\ C. Connor $\cdot$ S. Mann \\ Diabetes Department, Guy's and St Thomas' Foundation Trust, \\ London, UK
}

\author{
A. Du Chemin \\ Sutton and Merton Diabetic Eye Screening Programme, \\ London, UK \\ S. Sivaprasad \\ Department of Ophthalmology, King's College Hospital, \\ London, UK
}

